\title{
Why Formal Logic is Essential for Critical Thinking ${ }^{I}$
}

\section{Donald Hatcher}

\author{
Baker University
}

Résumé: Je crítique les arguments avancés contre l'usage de la logique formelle dans la formation de la pensée critique. Ensuite j'avance des raisons théoriques, pratiques et empiriques pour montrer que l'enseignement des rudiments de la logique formelle est essentiel à une telle formation, et que ceux-ci devraient donc s'enseigner dans tous les cours censés de former la pensée critique.

Keywords: critical thinking, formal logic, informal logic, composition, critical writing, critical thinking assessment, critical thinking pedagogy

\section{Introduction}

In a time when the nature and value of rationality have come into question, when minds, both young and old, appear to be ruled more by the forces of media manipulation or political rhetoric than by rational reflection, and when, according to a survey by the National Science Foundation, more Americans believe in astrology than in evolution, the critical thinking movement appeared to be the longawaited voice of sanity crying in a wilderness of irrationality. The very idea that large numbers of educators from across the disciplines were unabashedly claiming that students should, above all else, be taught to think critically stirred new hope in many of our hearts. What, other than the development of critical rationality, could be a more fitting goal for the education of human beings (as opposed to apes or parrots) in a democratic society?

In spite of the great potential of such renewed interest in developing students' rational capacities, there are, I believe, certain trends within the critical thinking movement that harm its potential effectiveness and diminish its continued appeal in the wider circles of education. ${ }^{2}$ One of these is a failure of critical thinking texts and courses to emphasize the importance of formal logic. While major figures in the critical thinking movement have offered a number of reasons to 
ignore or minimize instruction in the fundamentals of formal logic, I shall argue that such instruction is essential because it enhances students' abilities to understand, analyze, evaluate and articulate arguments-skills I hold essential to critical thinking. Hence, instruction in the fundamentals of formal logic should be an essential part of every critical thinking course.

By instruction in formal logic, I mean teaching the rudiments of sentential logic, with perhaps a minimum dose of quantification theory--just enough to legitimate inferences between universal, "for all $x$," statements and particular, "This is an $x$," statements. The courses should also show students how complex arguments can be paraphrased and put into standard argument form such as modus ponens, modus tollens, and hypothetical and disjunctive syllogisms. Such an approach is useful for evaluating arguments, that is, determining their validity, identifying missing premises or assumptions, and determining premise adequacy. This approach to argument evaluation is more useful than spending a lot of time on informal fallacies, which is often the focus of a critical thinking text. In fact, informal fallacies are of limited use when it comes to argument evaluation. Take, for example, a typical argument: that homosexuality is immoral because it is unnatural. There is no obvious informal fallacy here. But persons with minimum training in a formal approach to argument evaluation will see that this is an enthymeme missing the major premise that, "If something is unnatural, then it is morally wrong." Once this is pointed out, the argument is no longer the least bit convincing because the major premise is blatantly false; i.e., if being unnatural made something morally wrong, then playing the viola or using synthetic drugs to treat illness would be immoral. ${ }^{3}$ With a minimal understanding of formal logic, the problem with the argument is readily apparent; without such training, it is not clear exactly what is wrong with the argument, except perhaps some vague claim that the premise is not adequate or sufficient for the conclusion.

What follows is, first, a critical evaluation of some of the arguments given for not including instruction in formal logic in a critical thinking class. I shall then conclude the paper by offering reasons why it makes good pedagogical sense to include it.

\section{Some Criticisms of Formal Logic}

As those of you who have examined many of the critical thinking texts know, these texts (perhaps in an attempt to separate themselves from the traditional logic courses of old) tend pretty much to ignore instruction in formal logic. In so doing, they omit the formal character of reasoning which links logic to the methods of such disciplines as mathematics and science. ${ }^{4}$ For the most part, symbols are kept to a minimum, and there is no systematic treatment of symbolic logic. Analyses of such concepts as "logical form" and "entailment" are either missing or treated in an intuitive manner, relying on students' ability to imagine counter-examples to the kind of argument in question-an ability that few students seem to possess. 
The sins of omission are further complicated because some important writers in the critical thinking movement go so far as to speak out against formal logic as an adequate tool for critical thinking. For example, a few years ago, at the end of a thought-provoking paper on the importance of being aware of our background logics when making arguments, Richard Paul, concludes that, "The history of disciplines with their procedures and notational emphasis fails to provide an organon for everyday critical thought. We live as inferential beings enveloped in unformulated, deeply behavioral background logics. The logical system of the schools has little to do with the logic we live." That is, according to Paul, the organon of formal logic, begun with Aristotle, is not adequate to deal with the decisions and disagreements of real life. Rather than suggest ways that a formal approach to argument analysis might be revised to deal with "real world problems"-an approach I would recommend-Paul recommends a dialectical analysis void of any clear formal procedures.

Even if we grant that formal logic does not mirror how people actually argue and that the symbols and their "truth-values" have little to do with real life, what is wrong with Paul's position? One problem is a failure to distinguish between the actual practice of argumentation and critical thinking, and the normative standards that should guide such critical discussions. We engage in many human practices, but it does not follow that we "ought" to do them the way we do. For example, nine out of ten (honest) golfers have golf swings that will not allow them consistently to break 100 . It does not follow, however, that they ought to swing in that way, or that the $10 \%$ who have good swings cannot criticize those found lacking. In an analogous fashion, real world disagreements may be complicated and messy, but it does not follow that they cannot be clarified, making explicit people's assumptions or Paul's "background logic" and then evaluated along the lines prescribed in the beginning of the paper; i.e., put in standard form and checked for validity and the relevance and reasonableness of the premises.

Second, it would seem that Paul's prescribed dialectical approach to evaluating competing positions must itself assume some set of standards or "rules for discussion" in order for members of the discussion to know when a position has been adequately defended or should be rejected. I would suggest that beneath the informal rules for acceptability and rejection are the general rules of inference in formal logic and the canons for empirical research of the sciences-both physical and social. ${ }^{6}$ Without clear notions of "validity," "entailment," and scientific inductive logic, how can discussants "tell what follows" or know when a premise is acceptable with respect to evidence? Even if we begin with some version of an informal or dialectical approach to critical thinking, formal logic still has an essential role to play in helping us determine when a position is to be accepted or rejected.

Another example of such anti-formalist sentiments is given by Kerry Walters. Walters accuses typical critical thinkers of adopting a kind of methodological ab- 
solutism or "analytic reductionism." He claims (although I don't believe this actually happens) that in the typical critical thinking course, "One reduces an argument to its simplest constitutive propositional elements, examines these elements individually for truth-value and the relation to one another for logical form, and then decides whether the argument is good or bad." This, he believes, is an unacceptable procedure. It assumes a sort of "methodological absolutism" which is unwarranted and misleading. In other words, he believes there must be other acceptable ways to evaluate the reasonableness of a position. In an almost Kierkegaardian spirit, both Walters and Paul believe that "life's complexity" precludes analysis by the techniques of formal logic.

Neither Walters nor Paul shows in any detail just what the problem is or gives examples of arguments that cannot be paraphrased and then translated into standard form for evaluation. If the problem is the complexity of everyday discourse, this is a practical problem, and there is nothing inherently unintelligible about analyzing complex arguments into their parts and ultimately into standard logical patterns of premises and conclusions. ${ }^{8}$ This very process seems to me to be what many of Socrates's exchanges in the dialogues were all about: getting clear, for purposes of evaluation, on just what the person's position was, and then evaluating the reasons the person had for holding the position.

If the complaint is that the discourse of real life does not resemble the arguments found in a typical logic or critical thinking text, this can be solved by teaching students the skills of careful analysis and paraphrasing. If, in the course of a day's reading, there do not appear to be instances of valid deductive arguments, that does not mean arguments cannot be put in standard form-assuming the reader knows how - and then evaluated. One might also ask, why should the unstructured prose of the modern media be students' paradigm of good thinking? There are numerous classic texts that clearly exemplify valid argument patterns, if students are only taught to look; e.g., such Platonic dialogues as the Crito, and Meno, "The Declaration of Independence," some of the Federalist Papers, and hoards of essays by philosophers.

A third criticism of the use of formal logic in a critical thinking class comes from my students. Currently, many students are put off by mathematics. Upon taking my critical thinking course they have often told me that formal logic, with its symbolic notation and formulae, "looks a lot like math." I do not believe such a criticism to be unique to my university. Hence, in order not further to alienate those students who are intimidated by math, critical thinking texts avoid any extensive use of symbols. ${ }^{9}$

Nonetheless, even if some students have trouble with symbolic notation, to give up a useful tool for seeing the structure of arguments or structuring our own arguments is pandering to the desires of the weaker members of our educational community. If the symbolic techniques of formal logic are a valuable educational 
tool, then they should be used. When students come to us no longer able to read well, will we then give up assigning books? One fears to think of the answer.

Fourth, members of the critical thinking movement tend to believe that the traditional logic courses of old-Mental Gymnastics 101 - did very little to equip students to deal with the hard decisions we all frequently confront "in real life." The story is told of Howard Kahane teaching a traditional logic course in the $1960 \mathrm{~s}$ when a student asked how formal logic would help him decide whether to go to the Vietnam War. Kahane did not have an answer and so set out to write a new logic text, Logic and Contemporary Rhetoric: The Use of Reason in Everyday Life, now in its seventh edition. ${ }^{10}$ This argument against formal logic as a useful tool for critical thinkers is a strong one. One of the often-stated goals of critical thinking courses is to help students decide not only what to believe, but what to do. "But, if the formal symbolic methods of the old courses in logic were ineffective with respect to such decision-making, then it would seem reasonable to focus on non-symbolic approaches to argument analysis.

My question here is simple. Is there something inherently inadequate about formal logic, in its most general sense, that makes it ineffective in decision-making? I have not seen the arguments. If decision-making means the critical evaluation of alternatives with respect to consequences, what better way to eliminate an alternative than the combination of disjunctive syllogism and modus tollens, where the latter forces us to focus on the unacceptable consequences of one of the alternatives? Rather than writing a book on informal logic, perhaps Kahane would have done. well to see just what part of formal logic was useful for decision making and what part, i.e., proofs, should be left out. Hence, for the purposes of gaining popular acceptance for such an unquestionably valuable educational goal as critical thinking, non-formal approaches may indeed have merit. However, as we shall see, what is gained in popularity is far outweighed by other pedagogical considerations.

One final reason given to reject the use of formal logic in critical thinking instruction is that my own research, using pre- and post-testing, indicates that students who take a one-semester course in formal logic actually do worse on a standardized critical thinking test having taken formal logic. ${ }^{12}$ Students in an introductory logic class using Copi's text were given pre- and post-tests of the EnnisWeir Critical Thinking Essay Test. They scored one point lower on the post-test than on the pre-test. One could easily conclude that formal logic undermines students' critical thinking abilities and so should be ignored.

If the course in formal logic spent most of the time on truth tables, quantification theory, or proofs, rather than paraphrasing arguments and putting them in standard form for evaluation, then the results are not surprising. Such logic courses may well confuse students rather than empowering them. As the data summarizing the study show, ${ }^{13}$ students who are given instruction in the fundamentals of 
formal logic and shown how logic can be used to understand and evaluate arguments made significant gains on the Ennis-Weir test.

So it seems that if these are the typical arguments against using formal logic in a critical thinking course, the conclusion not to do so is not supported by either the arguments or evidence. First, critics of formal logic's role in critical thinking (Paul and Walters) have not shown that it is impossible to paraphrase complex arguments and put them in standard form for evaluation. Second, it seems that informal rules to guide critical discussions can be reduced to well-understood principles of formal logic. Third, research data indicates that, while formal logic that is not applied to analyzing and constructing real arguments has little positive effect, knowledge of the fundamentals of formal logic and its application to argument analysis and evaluation do help students become better critical thinkers.

What, though, are some pedagogical and conceptual arguments for the use of formal logic? The remainder of my paper will offer a kind of teleological argument, beginning with what I believe is the end or ideal toward which courses in critical thinking aspire, and showing, given the end, that an efficient means to attain it will include teaching the fundamentals of formal logic.

\section{The Importance of Formal Logic for Critical Thinking}

What then, in a most general sense, is the goal of teaching critical thinking? While there is considerable quibbling over this important question, ${ }^{14} \mathrm{I}$ believe most would agree that, at a minimum, the goal for critical thinking instruction is to teach students to be reasonable, that is, to appeal to reason as much as possible, in examining beliefs and making decisions that affect their lives. While such a conception of critical thinking is in accord with Harvey Siegel's idea that critical thinkers are people who are "appropriately moved by reasons,"15 such a conception also implies that, as persons for whom reason guides their decisions, critical thinkers should seek out alternative positions and evaluate them honestly before they make a choice. ${ }^{16}$ It seems obvious that, wherever possible, unless one has looked at alternative accounts or positions, and honestly evaluated them, one cannot say one has chosen wisely. Choosing without looking at the available alternatives would be like buying a car without driving other models, but yet claiming to have made the best choice.

How, though, does one go about evaluating alternatives with respect to their reasonableness? And, more importantly, what role does formal logic play in the process? The process of rational evaluation, I believe, contains three steps: clarification, evaluation, and articulation. ${ }^{17}$ The first step requires that we clarify and so clearly understand the position to be evaluated. To quote Bob Dylan, "Don't criticize what you don't understand." Obviously, such clarification can be tedious and difficult, especially when the claims are imbedded in the ill-formed rhetoric of much everyday discourse. But if evaluation is to occur, "getting clear" is essential. 
This conception of "getting clear" implies that we learn to see claims as conclusions to arguments, and the reasons given for the claims as premises intended for support. In other words, to evaluate an alternative position is to turn the position into an argument. The evaluation of the position is the second stage of critical thinking. Argument evaluation is complex. (In fact, perhaps with beginning students, we would be wise consciously to keep the arguments as simple as possible.) It can involve identifying hidden assumptions, presuppositions, or one's "background logic," as Richard Paul suggests. Upon closer analysis, unclear or ambiguous terms may be discovered. But beyond these difficult tasks, that no doubt require a good deal of practice, one must also have some way to tell if the premises adequately support the conclusion. It is important to see is that the critical evaluation of a belief - as all evaluation - assumes that the person engaged in the evaluation possesses some set of standards or tools by which he or she conducts the evaluation and arrives at a reasoned judgment. When evaluating arguments, such standards must, at a minimum, allow the persons to distinguish between "good arguments" and "bad arguments." Beliefs, then, which are reasonable to hold may be those beliefs which are the conclusions to good arguments. Beliefs which are unreasonable to hold are those which are not self-evident or for which no good argument has been provided. ${ }^{18}$ We might conclude, then, that reasonable persons are those who, after evaluating alternative positions, adopt those which have strong logical support, and who are at least skeptical of positions where such support is lacking. But such a private process of evaluation is not enough.

The final step in the critical thinking process is articulation, that is, presenting the evaluation process that led to one's conclusion. By carefully explaining the process that led to the conclusion one can more easily evaluate the reasonableness of the position, and, more importantly, share it with others for their critical comments. Stating arguments clearly is essential if others are to examine our ideas. When it comes to objective criticism, we are often our worst enemies (as our publishers never get tired of pointing out). As Ralph Johnson has said, contrary to those who emphasize the self-correcting aspect of critical thinking, critical thinking is best done in a community of inquirers. To publicly submit our ideas to criticism requires that we can articulate them and their supporting reasons so that others may understand and critique our ideas. ${ }^{19}$

If we accept this minimal description of the goals and methods of critical thinking, the question is: What means are most adequate in achieving these goals? As I have just argued, it seems any sort of critical evaluation requires knowledge and application of some standard for judgment. Without some standard, the person has no way of giving a justification for adopting one position over an alternative.

When students are asked to develop such a standard, ${ }^{20}$ there are at least three options: Either we use the informal techniques present in the typical critical thinking text or we explain how to evaluate arguments through the methods and con- 
cepts of formal logic, or we employ some combination. Now, it seems that to use only formal logic would be a mistake. To ignore informal fallacies could possibly turn critical thinking courses back into the old "Mental Gymnastics 101" courses which were both ineffective and unpopular. So the issue is whether critical thinking courses should teach both formal and informal logic or only informal.

If the goal is to explain as easily as possible to a naive or perhaps skeptical student those rational standards which allow us to see the difference between good and bad arguments, the formal approach has much to commend itself. First, the concepts used by formal logicians to evaluate arguments are clearly defined and well understood. Such concepts as "validity," "entailment," and "soundness" can be explained with a great deal of rigor. They are more easily understood than such notions in informal logic as relevance, sufficiency, and acceptability. ${ }^{21}$ If good reasoning is "truth preserving," students see that the most reasonable belief one can have is one which is supported by reasons or premises that, if true, would guarantee the truth of the belief, and, just as importantly, there is good inductive evidence for the premises. If such a necessary relation between the truth of one's beliefs and the truth of the reasons for the belief is the ideal, then the rationality of all other beliefs can be evaluated in light of this ideal. Students should, of course, be told that such certainty is the ideal, and ideals are hard to realize. Nonetheless, a clear notion of sound arguments as an intellectual goal is important for evaluating arguments. The more closely arguments resemble sound deductive arguments, the better.

The process of articulation, the third stage of critical thinking, is also greatly aided by a fundamental knowledge of formal logic. Use of such formal patterns as modus tollens and disjunctive syllogism allows our readers to better understand our position and the reasons for holding it. Using a modus tollens argument pattern to show the problematic consequences that follow from not accepting a position is an extremely clear way of arguing a point. For example, if not teaching students the fundamentals of formal logic and how they apply to all reasoning entails that students (1) lack a clear standard by which to evaluate arguments, (2) cannot present their own ideas in a clear forceful fashion, and (3) have trouble organizing the arguments they encounter, then it follows that we should teach students the fundamentals of formal logic.

There are also psychological reasons for emphasizing formal logic. Psychologically, the critical evaluation of personal beliefs becomes much easier when students realize that the evaluation is the evaluation of "an argument," rather than their beliefs qua theirs. Arguments do not have personalities or egos. They have premises and conclusions, and valid deductive arguments are of such a form that if one accepts the premises one must accept the conclusion. Strong inductive arguments are such that if the premises were true, it is likely that the conclusion is also true. Such an ideal of critical thought is both depersonalized and de-mystified. The critical evaluation of a belief, at least for the most part, becomes a formal 
process, and the beliefs students and others hold become subject to criticism by virtue of the impersonal rules governing the evaluative process. Critical evaluation is moved beyond the realm of personal feelings or popularity polls. Students understand and, even more importantly, appreciate the rigor and force of a valid logical argument. And, as I have argued elsewhere, with such rigor comes respect for the discipline. ${ }^{22}$ Students come to understand clearly what it means, as Socrates said at the end of the Meno, "to tie their beliefs down with reasons." They know, as perhaps they have never known before, the force of the statement, " $x$ logically entails $y$," regardless of their intuitions or feelings or how many of their friends believe it.

In addition to these arguments, there are additional pedagogical concerns which those who still prefer the alternative of only an informal approach must answer. Assuming that we agree that it is important to understand the statement that "Some claim does or does not entail some other claim," we should ask: Can students understand the nature and necessity of entailment without first having a clear notion of validity? And, can they understand validity without a clear notion of logical form? And, can they understand logical form without some knowledge of how to symbolize arguments so that the formal relation between premises and conclusions is made readily apparent? I believe not-at least not without a lot of unnecessary effort. An adequate explanation of logical form requires the notion that arguments in natural language can (at least ideally) be paraphrased and then reduced to symbolic form, displaying their logical structure. It would follow, then, that if understanding the nature of logical entailment is essential for providing a standard for evaluating arguments, then the fundamentals of formal logic are essential for such a task. To ignore such material in any course which proposes to teach critical thinking and teach only informal approaches is not sound pedagogy.

Another pedagogical reason for teaching students the fundamentals of formal logic is that, as I have found, informal fallacies - the heart of many critical thinking texts-are more easily understood once students understand formal logic. They see that most informal fallacies are fallacies because the conclusion is not entailed or supported by the premises, no matter how convincing the argument may sound. This is especially true of $t u$ quoque fallacies, which, I suppose because hypocrisy is a moral vice, students have trouble understanding. But once they are familiar with the canons of formal reasoning, they easily see that the fact that persons engage in the very acts they criticize has nothing to do with whether their criticisms are reasonable or not.

Such conclusions concerning pedagogy are not simply based on a conceptual analysis of the goals of teaching critical thinking. They have also been born out in the teaching of my old "Mental Gymnastics 101" logic courses. Whenever informal fallacies were covered before formal logic, students would suggest on their course evaluations that the material would be more understandable if it were "taught backwards." That is to say, it is easier to understand informal fallacies once one 
understands formal logic and the requirements for validity. If most courses in critical thinking continue to emphasize informal logic and fallacies, it would seem that these could be taught more easily if the fundamentals of formal logic were covered first.

Some may object and say that validity is the least important question when evaluating arguments. The more important question in most disputes is whether the premises given in support of the belief are acceptable or not. Such observations are indeed accurate. Nonetheless, the process of evaluating the truth of premises can also be enhanced by the study of formal logic. For example, one strategy is to ask students to turn the premise in question into a conclusion, and then ask, "What sorts of premises are needed in order to support such a conclusion?" For example, if an argument by Rush Limbaugh against voting for Clinton included the premise that "Clinton is a socialist," and students wanted to assess the claim, he or she might construct a modus tollens argument that defined a socialist and then see if Clinton had those properties. For example: (1) If someone is a socialist, then he or she believes in state ownership of the means of production and relative equalization of income. (2) Clinton, as far as we know, does not endorse either of these beliefs. Hence, (3) Clinton is not a socialist. Obviously, understanding the power of such valid argument patterns makes the process of constructing arguments and evaluating premises much easier.

\section{Conclusion}

So, there seem to be some strong arguments for teaching (even emphasizing) the fundamentals formal logic in critical thinking courses, and it is unwise to leave it out or to criticize it, as some have done. While knowledge of formal logic is not sufficient to make people good critical thinkers, to ignore it limits the appreciation students have for the rigor which is at least possible in human thought and deprives them of a valuable tool for constructing and evaluating arguments.

\section{Notes}

' For earlier treatments of some of these issues see my article, "A Critique of Critical Thinking," Teaching Thinking and Problem Solving, Volume 7, Issue 10, December 1985. An earlier version of this paper was given at the 16th International Conference on Critical Thinking and Educational Reform, July 29, 1996 at Sonoma State University.

${ }^{2}$ Another problem that threatens the credibility of the critical thinking movement is the paucity of research being done to evaluate (and hopefully validate) the claims about the effects instruction in critical thinking has on students. Like it or not, in educational circles of the 90 s, legitimacy requires assessment. Another trend that is problematic is a tendency for some critical thinkers to endorse relativism in one form or another. (See, for example, Robert Sutton's "The Right Method?," Inquiry: Critical Thinking Across the Disciplines, 11 (February, 1993), 12-14.) It seems obvious that one cannot apply critical standards to issues across the disciplines without 
endorsing a set of standards of rationality that will apply across the disciplines.

${ }^{3}$ I am grateful to my friend, Professor Don Marquis, at the University of Kansas for this example.

${ }^{4}$ According to Ralph H. Johnson and J. Anthony Blair, paraphrasing Perelman and OlbrechtsTyteca's The New Rhetoric, "One should look to see whether argumentation conforms to certain basic rules of procedure rather than to the model of geometric demonstrations ... the component functions in argumentation are more plentiful and varied than merely the advancing of premises for conclusions . . " in "The Recent Development of Informal Logic," in The Rise of Informal Logic (Newport News: Vale Press, 1996), pp. 6-7.

"Richard Paul, "Background Logic, Critical Thinking, and Irrational Language Games," Informal Logic, Vol. VII, \#l, Winter 1985, p. 17. Reprinted in Paul's Critical Thinking: What Every Person Needs to Survive in a Rapidly Changing World, ed., A.J.A. Binker (Rohnert Park, CA.: Center for Critical Thinking and Moral Critique, 1990), pp. 68-86.

${ }^{6}$ For an example of such rules to lead a critical discussion, see Chapter Two of $L$. Anne Spencer's and my Reasoning and Writing: An Introduction to Critical Thinking (Lanham, MA.: Rowman and Littlefield, 1993), pp. 19-21. Edward Damer's text, Attacking Faulty Reasoning, 3rd edition (Belmont, CA.: Wadsworth Publishing, 1995), also contains what he calls "A Code of Conduct for Effective Rational Discussion," pp.172-186). We both got the idea from Frans H. van Eemeren and Rob Grootendorst in their article "Rules for Argumentation in Dialogues, Argumentation 2 (4), November 1988, pp. 499-510.

What Spencer and I tried to do in Reasoning and Writing was show that apparently informal rules for accepting and rejecting a position imply the basic concepts in formal logic. For example, a principle needed for successful critical discussion is for discussants to have some agreed upon way to reject a position as unreasonable: A Rejection Principle. Such a principle could be explicated in terms of reductio ad absurdum strategies; i.e., the position entails a contradiction or something agreed to be false; showing the argument's invalidity, i.e., that the premises, even if true, do not entail the conclusion; or that premises of the argument are highly questionable, given the available evidence.

${ }^{7}$ Kerry Walters, "Critical Thinking in Liberal Education: A Case for Overkill?," Liberal Education, Fall 1986, pp. 233-244. These same themes run through Walter's introduction to his ReThinking Reason: New Perspectives in Critical Thinking (New York: SUNY Press, 1994), pp. 122. He calls the introduction "beyond logicism." For my critique of Walters's position see "Is Critical Thinking Guilty of Unwarranted Reductionism?," Journal of Thought. Vol. 24, Spr-Sum 89, pp. 94-111.

"In fact, while he does not emphasize trying to put arguments in standard deductive form, this is the sort of exercise Edward Damer emphasizes in his critical thinking text, Attacking Faulty Reasoning. "One will seldom encounter an argument in so clear a form, but any argument can be reconstructed ... by the orderly separation of the premises from the conclusion." (p.6) I assume that if we can locate the premises and conclusion, we can supply any missing premises and put the argument into standard form.

${ }^{9}$ Art Skidmore, a former teacher of mine at the University of Kansas, once went so far as to write a logic text that covered first-order predicate calculus without using symbols. Everything was "spelled out."

${ }^{10}$ Logic and Contemporary Rhetoric, 7th edition (Belmont, CA.: Wadsworth Publishing, 1995).

"Robert Ennis's often cited definition of critical thinking is "reasonable reflective thinking about what to believe and do." This was first formulated nearly thirty-five years ago in his paper "A Concept of Critical Thinking," Harvard Educational Review, 32, No. 1, 1962, pp. 81-111.

${ }^{12}$ See my article, "Combining Critical Thinking and Written Composition: The Whole is Greater than the Sum of the Parts," Inquiry: Critical Thinking Across the Disciplines, Winter, 1995, Vol. $15, \# 2$, pp. 20-36. While the expressed purpose of this six-year study was to see how Baker students would do if they took our two-semester course that integrated critical thinking and 
written composition compared to students who took traditional one-semester courses in logic or critical thinking and composition, one of the surprising results was that the one-semester sections of logic and critical thinking actually did worse on the post-test of the Ennis-Weir Critical Thinking Essay Exam than on the pre-test. The following chart summarizes the results.

\section{Comparison of Ennis-weir Pre- and Post-Test Scores for Baker University Freshmen from Fall 1990 to Spring 1996}

$\begin{array}{llll}\text { Baker } & \text { Pre } & \text { Post } & \\ \text { Freshmen } & \text { E-W } & \text { E-W } & \text { Diff } \\ 90 / 91(n=169) & 6.3 & 12.4 & 6.1 \\ 91 / 92(n=119) & 9.4 & 12.2 & 2.8 \\ 92 / 93(n=178) & 6.8 & 12.6 & 5.8 \\ 93 / 94(n=178) & 8.1 & 14.1 & 6.0 \\ 94 / 95(n=164) & 7.5 & 13.0 & 5.5 \\ 95 / 96(n=169) & 6.9 & 12.9 & 6.0 \\ \text { Means (n=977) } & 7.5 & 12.8 & 5.3 \\ & & & \\ \text { Comparison Groups: } & & & \\ \text { Standard Logic } & 11.2 & 9.5 & -1.7 \\ \begin{array}{l}\text { (F94 } n=44) \\ \text { Standard }\end{array} & & & \\ \text { Critical Thinking } & 12.1 & 13.7 & +1.6 \\ \text { (S92 } n=23) & & & \\ \text { Means (n=67) } & 11.7 & 11.6 & -0.10\end{array}$

\section{Baker Freshmen}

to Senior Comparison: Fr.

Sr.

14.6

14.1

14.3
S.D./Sig.

$5.53 \% .000$

Means $(n=207)$

What can we make of these figures? For the Ennis-Weir Critical Thinking Essay Test, Baker freshmen who completed the critical thinking/composition sequence had an average increase of 5.2 points. The possible range of test scores is from -9 to +29 , although very few students score over 20. The ANOVA analysis of variance yields a standard deviation of 5.53, a statistical significance of .000 , and an $F$ value of 77.6 for Baker students. Intergrader reliability, always a concern for the Ennis-Weir exam, has ranged from .85 to over 90 over the six years. In all cases, the post-test was given as part of students' final exams. The Ennis-Weir scores of the comparison groups who took traditional one-semester logic or critical thinking courses decreased an average of 10 points. One comparison group at the large state school was comprised to two sections of a standard elective logic course using popular textbooks. Because the course was an elective, the students scored well on the pre-test (12.6 average), while scores declined on the post-test ( 11.5 average). The critical thinking course was taught at a large community college and used a standard critical thinking text, with no attempt to integrate critical thinking with composition skills. Their gain of 1.6 points was modest, but well below the average gain of +5.2 for Baker students. 
${ }^{13}$ See note 12.

${ }^{14}$ Ralph Johnson, co-author of Logical Self-Defense (McGraw-Hill), points out the importance of teachers having a clear notion of critical thinking. Without a clear notion of what critical thinking is, how will one test to see if students have become better critical thinkers?

${ }^{15}$ Harvey Siegel, Educating Reason: Rationality, Critical Thinking and Education (New York: Routledge, 1988), p. 22. See all of Chapter Three for Siegel's account of critical thinking.

${ }^{16}$ I am indebted to Connie Missimer for pointing out the importance of evaluating alternative theories or arguments for people who wish to be honest critical thinkers. See her text, Good Arguments: An Introduction to Critical Thinking (Englewood Cliffs, NJ: Prentice Hall, 1986), Chapter Three. One cannot, as J.S. Mill pointed out in Chapter Two of On Liberty, claim to be a critical thinker without being aware of the arguments on the other side of one's favorite position.

${ }^{17}$ This three-step process is discussed fully in Anne Spencer's and my text, Reasoning and Writing: An Introduction to Critical Thinking (Lanham, Md.: Rowman and Littlefield, 1993.)

${ }^{18} \mathrm{I}$ am assuming here a sort of Cliffordian ethics of belief where belief should be proportional to the evidence and arguments, not to psychological appeal or emotional need.

${ }^{19} \mathrm{Johnson's} \mathrm{remarks} \mathrm{were} \mathrm{from} \mathrm{a} \mathrm{presentation} \mathrm{to} \mathrm{new} \mathrm{faculty} \mathrm{at} \mathrm{Baker} \mathrm{University} \mathrm{who} \mathrm{were}$ interested in teaching critical thinking May 26, 1996. They are echoed is his paper "The New Logic Course: The State of the Art of Non-Formal Methods of Argument Analysis," The Rise of Informal Logic, p.56.

${ }^{20}$ Let's assume here that an epistemological relativist is not teaching the course and pushing culturally-based standards, which tum out not to be standards at all.

${ }^{21}$ For examples of informal logic's treatment of such concepts for argument evaluation, see Ralph H. Johnson and J. Anthony Blair's Logical Self-Defense, U.S. edition (New York: McGrawHill, 1994), pp. 54-55 and Edward Damer's Attacking Faulty Reasoning, 3rd edition, pp. 12-16. ${ }^{22}$ "The Failure of the Humanities in a Technological World," Liberal Education, Fall 1985.

Donald Hatcher, Director, Center for Critical Thinking, Baker University Baldwin City, Kansas 66006 U.S.A. 